\title{
Dietary intake of heterocyclic amines in relation to socio- economic, lifestyle and other dietary factors: estimates in a Swedish population
}

\author{
U Ericson ${ }^{1,2, *}$, E Wirfält ${ }^{1}$, I Mattisson ${ }^{1}$, B Gullberg ' and K Skog ${ }^{3}$ \\ ${ }^{1}$ Department of Clinical Sciences at Malmö, Lund University, Malmö, Sweden: ${ }^{2}$ Nutritional Epidemiology, Clinical \\ Research Center, House 60, Level 13, University Hospital MAS Entrance 72, SE-205 02 Malmö, Sweden: \\ ${ }^{3}$ Department of Food Engineering, Technology and Nutrition, Lund University, Sweden
}

Submitted 11 October 2005: Accepted 17 May 2006: First published online 23 March 2007

\begin{abstract}
Objectives: To estimate the dietary intakes of heterocyclic amines (HCAs), to examine the intakes in relation to socio-economics, lifestyle and other dietary factors and to compare the classification of subjects by intake of HCA versus intake of meat and fish. Design: Cross-sectional analysis within the Malmö Diet and Cancer (MDC) cohort. Data were obtained from a modified diet history, a structured questionnaire on socioeconomics and lifestyle, anthropometric measurements and chemical analysis of HCAs. HCA intake was cross-classified against meat and fish intake. The likelihood of being a high consumer of HCAs was estimated by logistic regression analysis. Dietary intakes were examined across quintiles of HCA intake using analysis of variance.

Setting: Baseline examinations conducted in 1991-1994 in Malmö, Sweden. Subjects: A sub-sample of 8599 women and 6575 men of the MDC cohort.

Results: The mean daily HCA intake was $583 \mathrm{ng}$ for women and $821 \mathrm{ng}$ for men. Subjects were ranked differently with respect to HCA intake compared with intake of fried and baked meat and fish $(\kappa=0.13)$. High HCA intake was significantly associated with lower age, overweight, sedentary lifestyle and smoking. Intakes of dietary fibre, fruits and fermented milk products were negatively associated with HCA intake, while intakes of selenium, vegetables, potatoes, alcohol (among men) and non-milk-based margarines (among women) were positively associated with HCA intake.

Conclusions: The estimated daily HCA intake of $690 \mathrm{ng}$ is similar to values obtained elsewhere. The present study suggests that lifestyle factors (e.g. smoking, physical activity, fruit and vegetable intakes, and types of milk products and margarines) may confound associations between HCA intake and disease. The poor correlation between HCA intake and intakes of fried meat and fish facilitates an isolation of the health effects of HCAs.
\end{abstract}

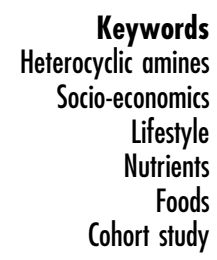

Epidemiological studies have indicated that diet is an important factor in the global variation of human cancer rates and the importance of dietary components for cancer development has been generally accepted. Doll and Peto estimated in 1981 that $10-70 \%$ of all cancer in the USA could be related to diet ${ }^{1}$. The mutagenic/carcinogenic heterocyclic amines (HCAs) in cooked foods have been discussed in the aetiology of human cancer $^{2}$. The first report on high mutagenic activity in cooked meat appeared almost 30 years ago ${ }^{3,4}$; since then much research has been devoted to studying various aspects of HCAs, such as their formation, occurrence in foods, levels of exposure, metabolism, dietary factors that influence their uptake and biotransformation, and hereditary factors that influence the metabolism of these dietary carcinogens 5 .
The molecular structures of two of the most abundant HCAs, MeIQx (2-amino-3,8-dimethylimidazo[4,5- $f$ ]quinoxaline) and PhIP (2-amino-1-methyl-6-phenylimidazo[ $4,5-b]$ pyridine), are shown in Fig. 1.

HCAs are absorbed and metabolised by humans; urinary metabolites of HCAs have been used as biomarkers of recent exposure $^{6-8}$. However, since most HCAs are excreted within $24 \mathrm{~h}$, urinary HCA excretion does not reflect the usual intake. HCAs have been shown to form adducts with DNA in humans; for example, PhIP-DNA adducts were found in breast milk from mothers eating their normal diet ${ }^{9}$. Based on animal studies, the International Agency for Research on Cancer classified one HCA as a probable and eight HCAs as possible human carcinogens ${ }^{10}$. Sugimura ${ }^{11}$ drew the conclusion that although neither single HCAs nor the sum 

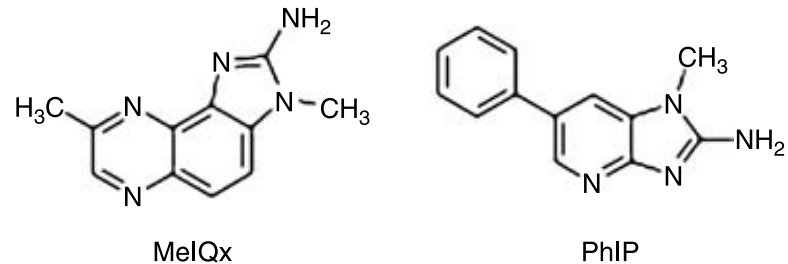

Fig. 1 Molecular structures of two of the most abundant heterocyclic amines: 2-amino-3,8-dimethylimidazo[4,5- $f$ ]quinoxaline (MelQx) and 2-amino-1-methyl-6-phenylimidazo[4,5-b]pyridine (PhIP)

of HCAs could explain the incidence of human cancer, compounds with similar mutagenic and carcinogenic potencies to HCAs would not be allowed as food additives. In a compilation of human studies investigating the incidence of cancer in different sites, $80 \%$ of the studies showed positive correlations with intakes of red meat, welldone meat, HCAs or meat preparation methods ${ }^{12}$. Most epidemiological studies on cancer and intakes of HCAs have focused on colorectal cancer and support the experimental evidence $^{13-15}$.

Accurate assessment of the intake of HCAs is of crucial importance in epidemiological studies. This requires not only dietary assessment methods that allow respondents to report cooking methods and to describe and quantify their consumption of cooked foods accurately, but also reliable data on the concentrations of HCAs in the foods. The amounts of HCAs vary with food type and cooking conditions: the levels of most HCAs generally range from not detectable to $20 \mathrm{ngg}^{-1}$; however, PhIP is typically found in amounts up to $35 \mathrm{ng} \mathrm{g}^{-1}$, but there are some reports of much higher levels 5 . The amounts of HCAs are in most cases higher in cooked meat than in cooked fish, and higher in pure meat than in mixed meat products, e.g. meatballs and sausage ${ }^{5}$. Commercially cooked food products generally contain low amounts, but there are exceptions ${ }^{16,17}$. Considerable amounts of HCAs formed during the cooking of meat are found in the pan residues ${ }^{5}$. Thus the intake of HCAs is influenced by the food choice and cooking method, as well as portion size and consumption frequency. Estimated average daily HCA intake reported in studies ${ }^{18-24}$ of different populations combining analytical data on HCA concentrations in cooked foods with data from food consumption surveys range from less than $1 \mathrm{ng} \mathrm{kg}^{-1}$ to almost $26 \mathrm{ng} \mathrm{kg}^{-1}$.

The primary aim of the present study was to estimate the intake of HCAs in a Swedish population based on the selfreported intake of cooked foods from the Malmö Diet and Cancer (MDC) cohort, combined with data on the content of HCAs in various cooked food products. Because the intake of HCAs potentially is associated with common risk factors for chronic disease, the present paper also examines socio-economic and lifestyle factors and the dietary characteristics of individuals with high and low dietary HCA intake.

\section{Methods}

\section{MDC study}

The MDC study is a prospective cohort study in Malmö, a city in the south of Sweden with approximately 250000 inhabitants. In 1991, the MDC source population was defined as all persons living in the City of Malmö and born between 1926 and 1945. In May 1994 the source population was extended to 74138 subjects, including women born between 1923 and 1950, and men born between 1923 and 1945. The MDC study was approved by the Ethical Committee at Lund University (LU 51-90). Details of the recruitment procedures and the cohort are described elsewhere ${ }^{25}$. Briefly, participants were invited by personal letter or came spontaneously after invitation by advertisement in local newspapers, in public places or in primary health-care centres. Inadequate Swedish language skills and mental incapacity were the only exclusion criteria; this left 68905 eligible persons ${ }^{26}$. The participants visited the MDC screening centre twice. During the first visit, groups of six to eight participants were instructed how to register meals in a menu-book and how to fill out the diet questionnaire and the extensive questionnaire covering socio-economic and lifestyle factors. Nurses drew blood samples, registered blood pressure and made anthropometric measurements. All questionnaires were completed at home. During the second visit, approximately 10 days after the first, the socio-economic questionnaire was checked and a dietary interview conducted. In October 1996, when recruitment closed, 28098 participants had completed all baseline examinations ( $41 \%$ of the eligible subjects).

\section{Study population}

The study population in the present work is a sub-sample including all participants who completed MDC baseline examinations between March 1991 and August 1994. In total 15174 subjects, 8599 women and 6575 men, are included.

\section{Dietary data}

The MDC study used an interview-based, modified diet history method ${ }^{27}$ that combined: (1) a 7-day menu-book for registration of lunch and dinner meals, cold beverages including alcohol, drugs, natural remedies and nutrient supplements; and (2) a questionnaire for assessment of meal pattern, consumption frequencies and portion sizes of regularly eaten foods. The consistency of the information provided was carefully checked so that the questionnaire and menu-book did not overlap. During the interview, participants were asked complementary questions on their usual meal pattern as well as on details about food choices and cooking methods (e.g. 'Was the pan residue used when making sauce and gravy?').

The mean daily intake of foods was calculated based on frequency and portion size estimates from the 
questionnaire and menu-book. The food intake was converted to energy and nutrient intakes using the MDC nutrient database, where the majority of the nutrient information comes from PC-KOST2-93 from the National Food Administration in Uppsala, Sweden.

In addition foods were classified in two separate systems. The first was based on the origin of the food item and fat/fibre content (if applicable). For instance, meat was classified according to origin and fat content (e.g. pork $>25 \%$ fat). Recipes were disaggregated into food items, which were assigned to their specific groups. The second system was based on food preparation methods (i.e. fried, deep-fried, baked, smoked and boiled). These dishes were not disaggregated into their ingredients.

The relative validity of the MDC method was evaluated in 1984-1985 in a sample of Malmö residents, 105 women and 101 men, 50-69 years old, using 18 days of weighed records, three days every second month during a year, as the reference method ${ }^{28,29}$. The Pearson correlation coefficients, adjusted for total energy, between the reference method and the MDC method, were (in women and men, respectively): 0.69 and 0.64 for fat, 0.71 and 0.64 for ascorbic acid, 0.44 and 0.46 for selenium, 0.69 and 0.74 for dietary fibre, 0.51 and 0.43 for low-fat meat, 0.80 and 0.40 for high-fat meat, 0.92 and 0.84 for meat products, 0.70 and 0.35 for fish, 0.77 and 0.60 for fruit, 0.53 and 0.65 for vegetables.

\section{HCAs in Swedish cooked foods; cooking procedures and chemical analysis}

Data on the HCA content in ordinary cooked Swedish meat and fish dishes were compiled from earlier published data on HCA in Swedish dishes ${ }^{5,30,31}$ because there is no common Swedish HCA database. The HCA data included pan-fried and oven-roasted red meat, chicken and fish, together with pan residues (drippings) cooked under wellcontrolled conditions. HCAs were extracted and concentrated using solid-phase extraction ${ }^{32}$. The analysis of HCAs is difficult because their concentration in food samples is very low, normally $0.01-20 \mathrm{ng} \mathrm{g}^{-1}$. The complexity of the matrix made standard addition calibration necessary to obtain reliable results. Using high-performance liquid chromatography coupled to ultraviolet detection or mass spectrometry, the standard deviation was generally below $10 \%$ and this is in agreement with results from other laboratories $^{33}$. Analytical data on the content of MeIQx, PhIP and DiMeIQx (2-amino-3,4,8-trimethylimidazo[4,5- $f$ ] quinoxaline) in samples cooked at 175 or $200^{\circ} \mathrm{C}$ were used in this study.

\section{Estimation of HCAs in food groups}

The average HCA content was estimated for 17 food subgroups, based on the type of food preparation method: fried meat, fried offal, fried sausage, fried minced meat, fried poultry, fried fish, baked meat, baked sausage, baked minced meat, baked poultry, baked fish, meat casseroles, poultry casseroles, fast food, complete dishes (e.g. meat/fish, potatoes and vegetables are included in the recipe), pasta sauces, and sauces and gravy made from pan residues. The HCA value for each group was calculated as a weighted average of the analysed HCA concentrations of the food items in the group. The weighting was based on MDC consumption data for different foods from the spring of 1993. For instance, for the group with fried minced meat, the HCA value was estimated from the HCA concentrations in meatballs [A], hamburgers [B] and stuffed cabbage rolls [C] and the proportions of these foods to the total consumption of fried minced meat: meatballs ( $a$ ), hamburgers $(b)$ and stuffed cabbage rolls $(c)$. Thus the formula for calculating HCA concentration in fried minced meat was: [HCA] $=$ $[\mathrm{A}] \times a+[\mathrm{B}] \times b+[\mathrm{C}] \times c$.

If information on HCA concentration for a food group was missing, values from a similar food group were used (e.g. data for baked minced meat was also used for baked meat).

Similarly, the value for sauce and gravy prepared from pan residues was calculated from weighted data on HCA content in pan residues from different types of meat, with the assumption that $100 \mathrm{~g}$ sauce and gravy contained pan residues from $100 \mathrm{~g}$ meat.

No information about the degree of surface browning was available from the dietary interviews. Two levels of HCA intake were estimated, based on HCA contents in foods fried at 175 or $200^{\circ} \mathrm{C}$. This paper focuses on estimates of HCA intakes from foods fried at the higher temperature, as this was considered to better correspond to ordinary cooking conditions.

\section{Dietary variables}

Intakes of total energy $\left(\mathrm{kJ} \mathrm{day}^{-1}\right)$ and the following nutrients were estimated: fat (percentage of energy, \%E), alcohol (\%E), fibre $\left(\mathrm{g} \mathrm{day}^{-1}(4.2 \mathrm{MJ})^{-1}\right)$, vitamin C $\left(\mathrm{mg} \mathrm{day}^{-1}(4.2 \mathrm{MJ})^{-1}\right)$, carotene $\left(\mathrm{mg} \mathrm{day}^{-1}(4.2 \mathrm{MJ})^{-1}\right)$, vitamin $\mathrm{E} \quad\left(\mathrm{mgday}^{-1}(4.2 \mathrm{MJ})^{-1}\right)$ and selenium $\left(\mu \mathrm{g} \mathrm{day}^{-1}(4.2 \mathrm{MJ})^{-1}\right)$. Intakes of the following food groups were also estimated $\left(\mathrm{g} \mathrm{day}^{-1}(4.2 \mathrm{MJ})^{-1}\right)$ : fruits including berries and fruit juice, vegetables including vegetable juice, boiled potato, fried and deep-fried potato, total potato, fermented milk products, non-fermented milk products, butter and milk-based margarine, non-milkbased margarine, white bread, fibre-rich bread.

Dietary intake of individual and total HCAs (ng day ${ }^{-1}$ ) was calculated from data on portion sizes, intake frequencies and estimated concentrations of HCAs in the different food groups. The following variables describing the energy-adjusted HCA intakes were examined: total HCA intake $\left(\right.$ ng day $\left.{ }^{-1}(4.2 \mathrm{MJ})^{-1}\right)$, the quintile ranking of individuals and the decentile ranking of individuals. The energy-adjusted intake of fried and baked meat and fish was also calculated $\left(\mathrm{g} \mathrm{day}^{-1}(4.2 \mathrm{MJ})^{-1}\right)$. In addition, the dietary HCA intake per kg body mass $\left(\mathrm{ng} \mathrm{kg}^{-1} \mathrm{day}^{-1}\right.$ ) was 
calculated based on the average body weights for men and women in the study population.

\section{Otber variables}

Year of interview was used to control for the variation associated with data collection procedures. Also, past change of dietary habits (based on the questionnaire item 'Have you substantially changed your dietary habits because of illness or another reason?'), dietary interviewer and season were examined as potential confounders of dietary relationships.

Information on sex and age was obtained from the personal identification number. Age was divided into 5-year categories. Participants were divided into five categories according to their highest level of education ( $<8$ years, 9-10 years, 11-12 years, 13 years, university degree).

Classification of socio-economic index was based on information on job title, tasks and position at work. The procedure was adapted from that of the 1989 Swedish population census ${ }^{34}$. In this study, the information was collapsed into five categories: blue-collar workers, whitecollar workers (low, medium and high) and self-employed. Retired and unemployed were classified according to their position before retirement/unemployment.

The smoking status of the participants was defined as smokers (including irregular smokers), ex-smokers and never smokers. Leisure-time physical activity was assessed using a questionnaire adapted from the Minnesota Leisure Time Physical Activity Questionnaire ${ }^{35,36}$. The number of minutes per week of 18 different activities was multiplied with an intensity coefficient and an overall leisure-time physical activity score was created. The score was divided into tertiles and categorised as low, medium and high. Body mass index (BMI; $\mathrm{kg} \mathrm{m}^{-2}$ ) was calculated from direct measurement of weight and height and a three-category variable was created $\left(<25,25-29, \geq 30 \mathrm{~kg} \mathrm{~m}^{-2}\right)$.

\section{Statistical analysis}

Crude mean intakes $\left(\mathrm{ng} \mathrm{day}^{-1}\right)$ and the percentile distributions of HCAs (MeIQx, DiMeIQx and PhIP, and total HCA at low and high temperatures) were calculated separately for women and men. The decentile distribution of calculated HCA intakes (ng day $\left.{ }^{-1}(4.2 \mathrm{MJ})^{-1}\right)$ was crossclassified against decentiles of the energy-adjusted intake of fried fish and meat $\left(\mathrm{g} \mathrm{day}^{-1}(4.2 \mathrm{MJ})^{-1}\right)$. Cohen's $\kappa$ was used to evaluate the agreement between the decentile distributions.

The likelihood of being a high consumer of HCAs (i.e. falling in the top quintile of energy-adjusted HCA intake) was estimated by logistic regression analysis. Separate models were created for age (5-year categories), education and socio-economic index, smoking status, leisure-time physical activity and BMI. Adjustment was made for year of dietary interview and past dietary change. The models were also created with additional adjustment for all socio-economic and lifestyle variables simultaneously. Age, physical activity and BMI were also tested for trends across quintiles. Finally, intake differences in energy-adjusted selected nutrients and food groups were examined across quintiles of energyadjusted HCA intake (ng day $\left.{ }^{-1}(4.2 \mathrm{MJ})^{-1}\right)$ using analysis of variance and adjusting for potential confounders (i.e. year of diet interview, change of dietary habits, education, smoking, leisure-time physical activity and BMI). Multiple comparison was performed with the Tukey test, $\alpha=0.01$.

Continuous variables were log-transformed prior to analysis to normalise distributions. The SPSS statistical computer package (version 11.0; SPSS Inc.) was used for all analyses.

\section{Results}

Table 1 displays estimated mean and percentile intakes of HCAs (PhIP, MeIQx and DiMeIQx) in the MDC cohort using data obtained for a low $\left(175^{\circ} \mathrm{C}\right)$ and a high $\left(200^{\circ} \mathrm{C}\right)$ pan/oven setting temperature. The estimated intake of HCAs is about 10 times lower for $175^{\circ} \mathrm{C}$ than for $200^{\circ} \mathrm{C}$. The rest of the results in this paper are based on HCA content in meat and fish cooked at a pan/oven setting of $200^{\circ} \mathrm{C}$, as we regard this temperature to reflect common cooking practices most appropriately. For $200^{\circ} \mathrm{C}$, the mean daily intake of HCAs was $583 \mathrm{ng}$ for women and $821 \mathrm{ng}$ for men. The mean daily intake for the whole group of women and men was 690 ng. PhIP contributed $60 \%$ of the dietary HCA intake. When adjusting for energy, the difference between men and women was less pronounced although

Table 1 Estimated intakes of heterocyclic amines $\left(\mathrm{ng} \mathrm{day}^{-1}\right)$ in a sample of women $(n=8599)$ and men $(n=6575)$ from the Malmö Diet and Cancer cohort, 1991-1994

\begin{tabular}{lrrrrr}
\hline & Mean & $\mathrm{P}_{25}$ & Median & $\mathrm{P}_{75}$ & $\mathrm{P}_{99}$ \\
\hline Women & & & & & \\
MelQx low & 22 & 13 & 20 & 29 & 58 \\
MelQx hight & 178 & 109 & 166 & 233 & 471 \\
DiMelQx low & 8 & 5 & 7 & 10 & 20 \\
DiMelQx high & 63 & 39 & 59 & 82 & 162 \\
PhIP low & 29 & 15 & 25 & 39 & 93 \\
PhIP high & 342 & 189 & 302 & 449 & 1094 \\
Total low & 59 & 36 & 54 & 76 & 157 \\
Total high & 583 & 344 & 536 & 767 & 1612 \\
& & & & & \\
Men & & & & 39 & 84 \\
MelQx low & 30 & 19 & 28 & 329 & 712 \\
MelQx high & 256 & 159 & 234 & 14 & 30 \\
DiMelQx low & 10 & 6 & 10 & 115 & 244 \\
DiMelQx high & 90 & 57 & 83 & 53 & 134 \\
PhIP low & 40 & 21 & 34 & 616 & 1463 \\
PhIP high & 475 & 272 & 422 & 104 & 231 \\
Total low & 81 & 50 & 74 & 1062 & 2289 \\
Total high & 821 & 496 & 746 & & \\
\hline & & & & &
\end{tabular}

$\mathrm{P}_{25}-$ 25th percentile; $\mathrm{P}_{75}-75$ th percentile; $\mathrm{P}_{99}-99$ th percentile; MelQX - 2-amino-3,8-dimethylimidazo[4,5- $f$ ]quinoxaline; DiMelQx - 2-amino3,4,8-trimethylimidazo[4,5-f]quinoxaline; PhIP - 2-amino-1-methyl-6-phenylimidazo[4,5- $b$ ]pyridine.

${ }^{\star}$ Low $=$ pan setting of $175^{\circ} \mathrm{C}$.

† High $=$ pan setting of $200^{\circ} \mathrm{C}$. 
significant: $279 \mathrm{ng} \mathrm{day}^{-1}(4.2 \mathrm{MJ})^{-1}$ for women and $297 \mathrm{ng} \mathrm{day}^{-1}\left(4.2 \mathrm{MJ}^{-1}\right.$ for men $(P=0.001)$ (not shown in Table 1). It should be noted that a small part of the population had very high HCA intakes; the intakes at the 99th percentile were about three times higher than the mean intakes in the population.

Cross-classifications were made to investigate if the food group variable estimating intakes of fried and baked meat and fish classified the subjects in the same way as the variable with detailed estimations of HCA intake. Table 2 displays the results for women. Only $21.7 \%$ of the women (sum of bold figures diagonally, 1868 out of 8599) were classified equally by the two variables $(\kappa=0.130)$. Among men $21.0 \%$ were classified equally $(\kappa=0.122)$ (data not shown). When comparing the estimation of HCA intake with the reported intake of all meat and fish (i.e. not only fried and baked foods) the corresponding results were $15.5 \%$ for women and $15.0 \%$ for men $(\kappa=0.061$ and 0.056) (data not shown).

The likelihood of falling in the highest quintile of HCA intake in relation to age, socio-economics, lifestyle and BMI is presented in Table 3. Season and dietary interviewer were not associated with HCA intake, and these variables are therefore not included in the multivariate analysis. In both sexes smoking, low leisure-time physical activity and overweight were characteristics for subjects in the highest quintile of HCA intake. High age reduced the likelihood of falling in the highest quintile of HCA intake. Women with 8 years or less of formal education were more likely to fall in the highest quintile of HCA intake. At first this also appeared to be the case for female blue-collar workers compared with medium and high white-collar workers, but this difference disappeared when all variables displayed in Table 3 were adjusted for each other (data not shown). Neither education nor socioeconomic status affected the likelihood among men.

Table 4 displays energy-adjusted intakes of nutrients and foods by quintiles of energy-adjusted HCA intake. In both women and men dietary fibre intake was negatively related to HCA intake. Intake of selenium was positively related to HCA intake. Among men, alcohol intake was also positively related to HCA intake. The consumption of all foods listed in Table 4, except white bread, varied significantly across quintiles of HCA intake. In both women and men, intakes of fruits, fermented milk products and fibre-rich bread were negatively associated with HCA intake, while intakes of vegetables and potatoes (boiled, fried including deep-fried and total) were positively associated with HCA intake. A positive association was also observed for intake of non-milkbased margarines among women. There was no tendency towards a linear association between intakes of nonfermented milk products and HCAs. Instead the highest intakes of non-fermented milk products were noted in the middle quintiles of HCA intake. Adjusting for change of dietary habits, BMI, age, leisure-time physical activity,

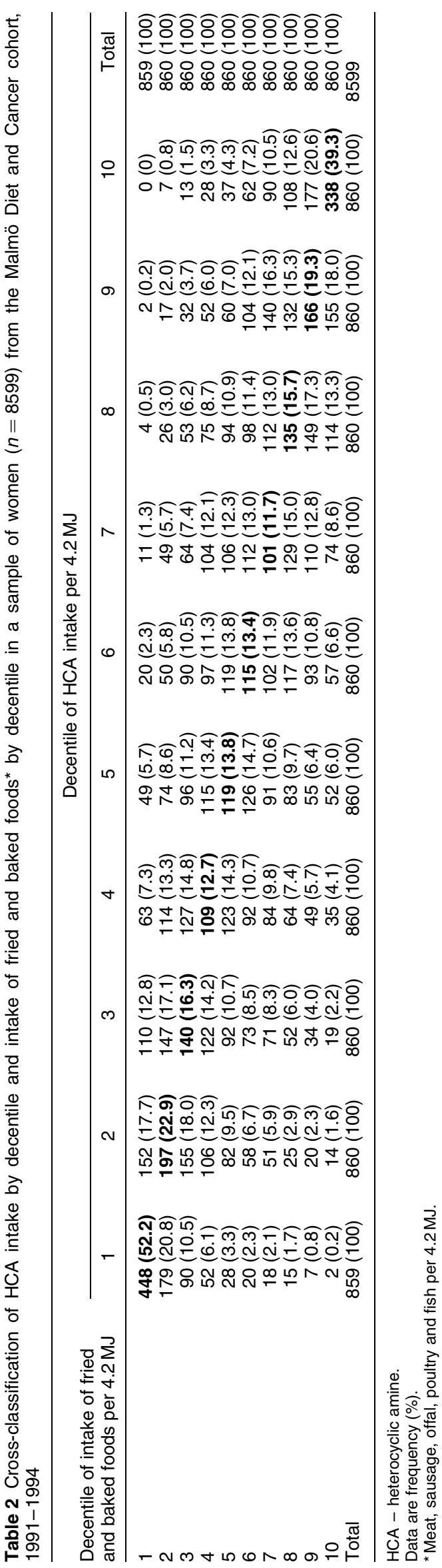


Table 3 The likelihood of falling in the highest quintile of HCA intake in relation to lifestyle, BMI, socio-economic factors and age in a sample of women $(n=8599)$ and men $(n=6575)$ from the Malmö Diet and Cancer cohort

\begin{tabular}{|c|c|c|c|c|c|c|c|c|}
\hline \multirow[b]{2}{*}{ Variable } & \multicolumn{3}{|c|}{ Women } & \multirow{2}{*}{$\begin{array}{c}P \text {-value } \\
\text { (test for trend) }\end{array}$} & \multicolumn{3}{|c|}{ Men } & \multirow{2}{*}{$\begin{array}{c}P \text {-value } \\
\text { (test for trend) }\end{array}$} \\
\hline & $n$ & $\mathrm{OR}^{\star}$ & $95 \% \mathrm{Cl}$ & & $n$ & $\mathrm{OR}^{*}$ & $95 \% \mathrm{Cl}$ & \\
\hline \multicolumn{9}{|l|}{ Age (years) } \\
\hline $46-49$ & 1068 & 1.00 & & $<0.001$ & 755 & 1.00 & & $<0.001$ \\
\hline $50-54$ & 2048 & 0.92 & $0.77-1.10$ & & 1603 & 1.13 & $0.92-1.40$ & \\
\hline $55-59$ & 1966 & 0.96 & $0.80-116$ & & 1472 & 1.04 & $0.83-1.29$ & \\
\hline $60-64$ & 2211 & 0.78 & $0.65-0.93$ & & 1718 & 0.93 & $0.75-1.15$ & \\
\hline $65-68$ & 1306 & 0.66 & $0.54-0.81$ & & 1027 & 0.65 & $0.51-0.84$ & \\
\hline \multicolumn{9}{|l|}{ Education } \\
\hline$\leq 8$ years & 3715 & 1.00 & & & 2956 & 1.00 & & \\
\hline $9-10$ years & 2609 & 0.85 & $0.75-0.96$ & & 1338 & 1.05 & $0.90-1.23$ & \\
\hline $11-12$ years & 533 & 0.87 & $0.70-1.09$ & & 797 & 0.92 & $0.75-1.12$ & \\
\hline 13 years & 626 & 0.80 & $0.64-0.99$ & & 588 & 0.89 & $0.71-1.12$ & \\
\hline University & 1071 & 0.63 & $0.52-0.76$ & & 852 & 0.84 & $0.69-1.02$ & \\
\hline \multicolumn{9}{|l|}{ Socio-economic index } \\
\hline Blue-collar worker & 3345 & 1.00 & & & 2276 & 1.00 & & \\
\hline White-collar worker, low & 2690 & 1.00 & $0.89-1.14$ & & 1014 & 0.86 & $0.71-1.04$ & \\
\hline White-collar worker, medium & 1354 & 0.81 & $0.69-0.96$ & & 1308 & 0.87 & $0.73-1.03$ & \\
\hline White-collar worker, high & 517 & 0.76 & $0.59-0.97$ & & 764 & 0.97 & $0.79-1.19$ & \\
\hline Self-employed & 565 & 0.97 & $0.78-1.21$ & & 1162 & 1.11 & $0.94-1.32$ & \\
\hline \multicolumn{9}{|l|}{ Smoking status } \\
\hline Never smoker & 3941 & 1.00 & & & 1885 & 1.00 & & \\
\hline Ex-smoker & 2274 & 1.09 & $0.95-1.24$ & & 2769 & 1.12 & $0.96-1.43$ & \\
\hline Smoker & 2349 & 1.29 & $1.14-1.47$ & & 1884 & 1.22 & $1.04-1.43$ & \\
\hline \multicolumn{9}{|l|}{ Leisure-time physical activity } \\
\hline Low & 1703 & 1.00 & & $<0.001$ & 1342 & 1.00 & & 0.001 \\
\hline Medium & 5052 & 0.84 & $0.74-0.96$ & & 3682 & 0.80 & $0.68-0.93$ & \\
\hline \multirow{2}{*}{\multicolumn{9}{|c|}{$\mathrm{BMI}\left(\mathrm{kg} \mathrm{m}^{-2}\right)$}} \\
\hline & & & & & & & & \\
\hline$<25$ & 4609 & 1.00 & & 0.001 & 2585 & 1.00 & & $<0.001$ \\
\hline $25-30$ & 2824 & 1.10 & $0.98-1.23$ & & 3168 & 1.39 & $1.22-1.60$ & \\
\hline$\geq 30$ & 1156 & 1.30 & $1.11-1.52$ & & 812 & 1.81 & $1.50-2.19$ & \\
\hline
\end{tabular}

$\mathrm{HCA}$ - heterocyclic amine; $\mathrm{BMI}$ - body mass index; OR - odds ratio; $\mathrm{Cl}$ - confidence interval.

${ }^{*}$ Adjusted for dietary change, year of diet interview and energy.

smoking and education (in addition to year of diet interview) did not substantially change the results.

According to Table 4, characteristic for both women and men in the 100th percentile of HCA intake appeared to be higher BMI, higher percentage of energy from alcohol, and higher energy-adjusted intakes of selenium and vegetables, but lower percentage of energy from fat and lower-energy adjusted intakes of fibre-rich bread, fermented and non-fermented milk products. Women in the 100th percentile had also lower intakes of fruits and berries.

\section{Discussion}

Our estimated mean dietary HCA intakes are in the same range as intakes observed in other studies (Table 5). To the best of our knowledge, no study has previously examined HCA intake in relation to lifestyle and socio-economic factors. Overweight, sedentary lifestyle and smoking were more common among men and women with high intakes of HCA. Their diets contained less dietary fibre, fibre-rich bread, fruits and fermented milk products, but more selenium, vegetables and potatoes. Men with high HCA intakes had higher intakes of alcohol, while women with high HCA intakes had higher intakes of non-milk-based margarines compared with the other groups. These relations have implications for interpretation of results in epidemiological studies.

The high relative validity of the dietary data ${ }^{28,29,37}$ and the large heterogeneous population are important advantages of our study. In addition, the estimated HCA intake includes HCAs from fish and information on whether the pan residues (drippings) from fried and roasted meat were used for the preparation of sauces, which is a common practice in Sweden. This information is important because the concentration of HCAs in pan residues is usually in the same range as that of cooked meat ${ }^{5}$. Furthermore, we have individual information on portion sizes of sauces and gravies in contrast to many other studies.

Unfortunately and similarly to most other studies on HCA intake, a special validation of the HCA intake has not been feasible. Urinary excretion of HCAs is an objective marker of HCA intake during the past $24 \mathrm{~h}$. However repeated collections of 24-hour urine samples combined with dietary records would be needed for assessment of usual intake. This is a costly undertaking, which currently is beyond our capacity. However, the high validity of the MDC dietary data and of the analytical data makes this 


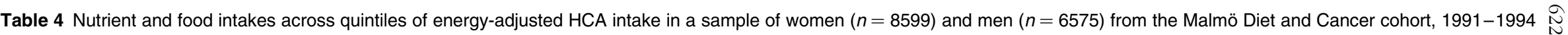

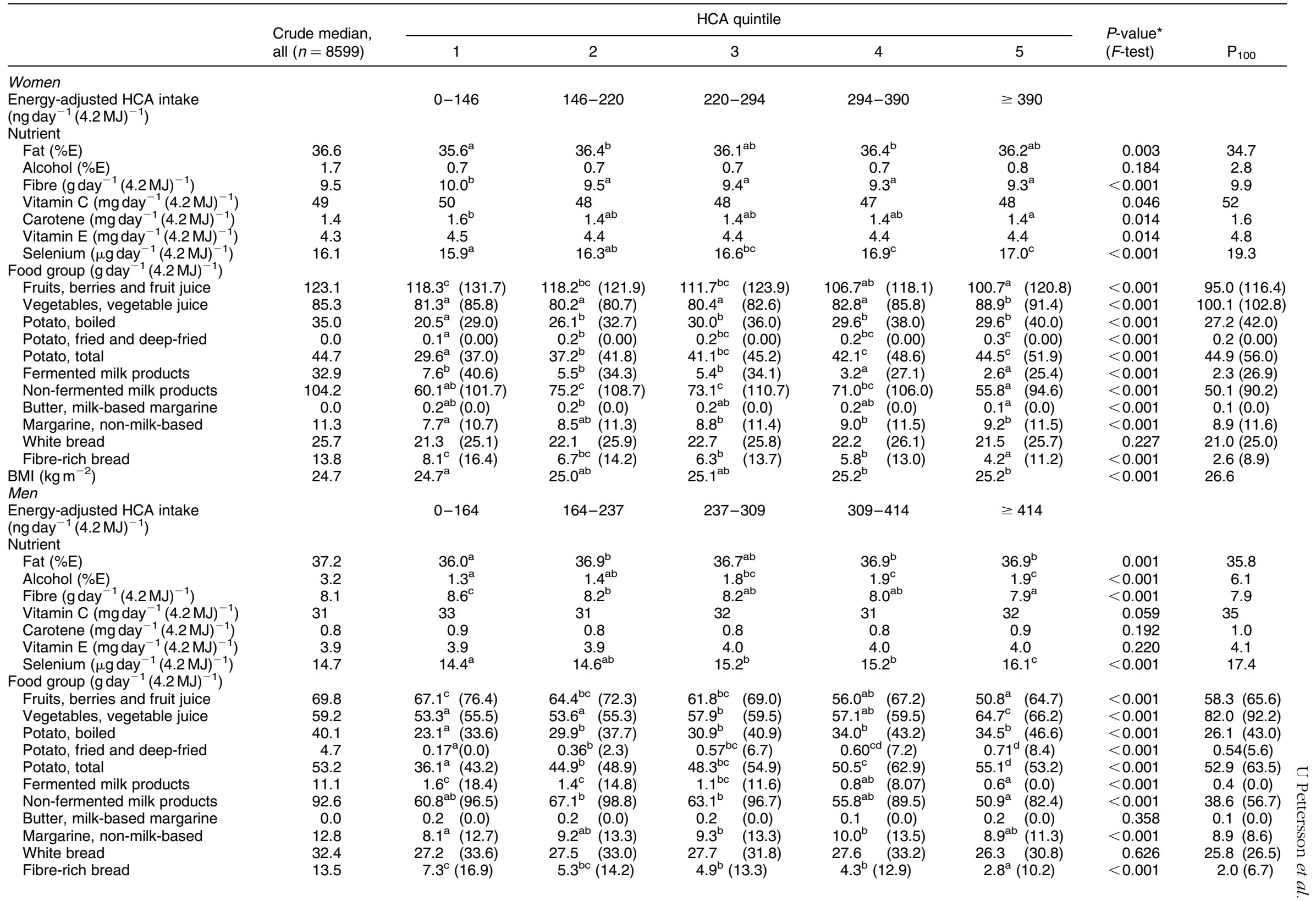


study estimating HCA intakes worthwhile. Cantwell et al. validated a food-frequency questionnaire (FFQ) against food diaries ${ }^{38}$. They found that the FFQ gave lower estimated intakes of MeIQx and PhIP. Since most of the HCA intake comes from lunch and dinner meals, which are registered in a food diary in the MDC study, our estimated HCA intake would probably be higher than in studies using an FFQ. The lack of individual estimations of the degree of surface browning or the level of doneness could be a limitation of our study. A decision was made to use HCA intake estimates from foods cooked at $200^{\circ} \mathrm{C}$, because this temperature gave a brown but not burnt frying surface and therefore most likely represents ordinary cooking conditions. Many other studies have included preferences of doneness and degree of browning (e.g. by using colour photographs) ${ }^{39}$. A linear relationship between HCA content and the degree of browning is, however, not evident ${ }^{40}$. For instance, some recent studies have indicated that background factors, such as genetic variations in pigs, may influence the appearance and the colour of fried meat ${ }^{41,42}$, and colour photographs may therefore be misleading when estimating HCA intake.

Several case-control and cohort studies have investigated the association between meat consumption and risk of cancer. The results are inconsistent, but the consumption of meat, red meat, fried meat and processed meat seems to elevate the risk of colorectal cancer ${ }^{12,13,43-46}$. Although the mechanisms behind these findings are not clear, consumption of HCAs formed during cooking is one of many potential explanations ${ }^{47}$. It is therefore important to separate the effects of HCAs from that of other characteristics of meat. To the best of our knowledge no study examining correlations between HCA intake and meat intake has been published. However, HCA intake and intake of well-done meat have in some studies shown similar positive associations with colon cancer ${ }^{13,15}$. On the other hand, Sinha et al. found that high intakes of MeIQx, unlike intakes of red meat, were significantly associated with colorectal cancer after mutual adjustments ${ }^{14}$. Table 2 shows that the variable for HCA intake and the variable for intakes of fried meat and fish classified the subjects differently in the present study. It cannot be excluded that the poor correlation is a consequence of low validity of the estimated HCA intakes. We are nevertheless inclined to believe that the results reflect true conditions, because the validity for both dietary data in general and analytical data was high. Besides, information on cooking methods and use of pan residues were thoroughly recorded. Therefore, compared with information from FFQs, the reported intakes rely to a lesser extent on memory.

In our study the average daily HCA intakes were $583 \mathrm{ng}$ for women and $821 \mathrm{ng}$ for men. These estimates are similar to those of other studies. Table 5 presents literature data on estimated intake of HCAs in different populations ${ }^{18-24}$. For estimations of HCA intake it is important to establish databases on HCA content in cooked foods that are 
representative for the eating habits of the population being studied. MeIQx, DiMeIQx and PhIP are among the most commonly detected HCAs in cooked foods ${ }^{48}$, and all studies in Table 5 include these HCAs. In some of the studies other HCAs are also included; for example, IQ (2amino-3-methylimidazo[4,5-f]quinoline) and MeIQ (2amino-3,4-dimethylimidazo[4,5- $f$ ]quinoline). According to our analytical data on HCAs in cooked Swedish dishes, IQ and MeIQ are not commonly detected and thus excluded from our study. As seen in Table 5, the estimated average HCA intakes range from $0.83 \mathrm{ng} \mathrm{kg}^{-1} \mathrm{day}^{-1}$ for subjects from Okinawa Island in Japan ${ }^{18}$ up to $26 \mathrm{ng} \mathrm{kg}^{-1}$ $\mathrm{day}^{-1}$ for the US population ${ }^{19}$. The average HCA intake in our study is $9 \mathrm{ng} \mathrm{kg}^{-1} \mathrm{day}^{-1}$ for women and $10 \mathrm{ng} \mathrm{kg}^{-1} \mathrm{day}^{-1}$ for men. The large variation in estimated HCA intakes may partly be caused by inclusion of different HCAs and the amount of analytical data. Dietary assessment methods could also affect the estimated HCA intake, but true differences in dietary habits (i.e. food preferences, intake frequencies, portion sizes, cooking methods, etc.) also influence the wide range of estimated intakes. For instance, fried meat is usually the main source of dietary HCA exposure in Western societies, but in Japan grilled fish contributes the most ${ }^{18}$. Our estimated HCA intakes are higher than those obtained in another Swedish study that reported a mean daily HCA intake of $117 \mathrm{ng}$ for women and $201 \mathrm{ng}$ for men, based on estimates from cooked meat, fish and gravy ${ }^{20}$. However, their estimation of HCA intake was based on average HCA content in meat cooked at lower temperatures than in our study. In addition, their dietary intake was assessed with an FFQ, a method that may result in lower estimated HCA intakes than with food records ${ }^{38}$.

The results from our study indicate that high dietary HCA intake is associated with smoking, low leisure-time physical activity and high BMI (Table 3). Although we are not aware of any studies that have investigated the association between the consumption of HCA-rich foods and other lifestyle factors, other studies have shown that diet is related to lifestyle factors like smoking and physical activity ${ }^{49,50}$ and also to $\mathrm{BMI}^{51}$. Thus future studies of the association between HCA and disease need to examine these variables as potential confounders or possible risk factors.

No clear intake differences of vitamin $\mathrm{C}$ and carotene were noticed between the HCA quintiles, possibly because the consumption trends of fruits and vegetables went in the opposite direction. It is logical that high selenium intakes were found among high consumers of HCAs because cooked meat and fish are important sources both of selenium ${ }^{52}$ and HCAs. The fact that potatoes and vegetables often accompany meat and fish in a meal could explain why intakes of potatoes and vegetables were positively correlated to HCA intake.

Dietary HCA intake close to or below the mean may not be a major health risk for subjects from the MDC cohort. However there was a substantial number of people with 
intakes far above the mean, e.g. the daily average in the 100th percentile for women was $1612 \mathrm{ng}$ (compared with $583 \mathrm{ng}$ for all) (Table 1). In a Swedish study an increased cancer risk was found only for dietary HCA intakes above $1900 \mathrm{ng}^{53}$. It must also be taken into consideration that some people may be more susceptible to genotoxic compounds than others ${ }^{54,55}$. Besides, other dietary characteristics can influence the outcome of genotoxic properties in HCAs. Subjects in the MDC cohort with high intakes of HCAs had lower intakes of two food components that may reduce the mutagenic/carcinogenic effects of HCAs - lactic acid bacteria from fermented milk products and dietary fibre - which can bind to HCAs and inhibit the mutagenic activity ${ }^{56-58}$. High intake of HCAs was also associated with low fruit consumption. Fruit probably have a protective effect against cancer in different sites ${ }^{59,60}$. On the other hand this may also apply to vegetables, and high consumers of HCAs had higher intakes of vegetables. Both fruits and vegetables contain many substances that might decrease the mutagenic activity of HCAs. For instance, breakdown products from cruciferous vegetables can affect enzymes involved in the metabolism of HCAs ${ }^{61}$, and flavonoids in onions, citrus fruits, apples, etc. may decrease the formation of HCADNA adducts ${ }^{62}$.

In conclusion, the main outcome of this study is that the addition of HCA values to our food database enhances our ability to separate HCA intake from that of other components in cooked meat and fish. Our estimated HCA intake was somewhat higher than in another Swedish study, but in the same range as results from studies of different populations. A tendency towards a less healthy lifestyle, including obesity, physical inactivity, smoking and low intakes of fruits, dietary fibre and fermented milk products, as well as high intakes of alcohol in men, was noted among subjects with high intakes of HCA. These findings will be of importance when investigating HCA intake in relation to cancer incidence in the population.

\section{Acknowledgements}

Source of funding: This work was supported by the Swedish Cancer Society, the Swedish Medical Research Council and the City of Malmö. It was also carried out with financial support from the Commission of the European Communities, specific RTD program 'Quality of Life and Management of Living Resources', QLK1-CT99-001197, 'Heterocyclic Amines in Cooked Foods - Role in Human Health'. It does not necessarily reflect its views and in no way anticipates the Commission's future policy in this area.

Conflict of interest declaration: There are no conflicts of interest.

Authorship responsibilities: U.E. was responsible for writing the manuscript and estimating HCAs in food groups, performed the data analysis and contributed to the study design. E.W. contributed to the study design, the interpretation of results and revision of the manuscript. I.M. contributed to the study design, the interpretation of results and revision of the manuscript. B.G. gave statistical advice and contributed to revision of the manuscript. K.S. was responsible for the compilation of data on HCA content in Swedish dishes and contributed to the study design, the interpretation of results and revision of the manuscript.

\section{References}

1 Doll R, Peto R. The causes of cancer: quantitative estimates of avoidable risks of cancer in the United States today. Journal of the National Cancer Institute 1981; 66(6): 1191-308.

2 Sinha R. An epidemiologic approach to studying heterocyclic amines. Mutation Research 2002; 506-507: 197-204.

3 Nagao $M$, Honda $M$, Seino $Y$, Yahagi $T$, Sugimura $T$. Mutagenicities of smoke condensates and the charred surface of fish and meat. Cancer Letters 1977; 2(4-5): 221-6.

4 Sugimura T, Nagao M, Kawachi T. Mutagens-carcinogens in food with special reference to highly mutagenic pyrolytic products in broiled foods. In: HiaH HH, Watson JD, Winsten JA, eds. Origins of Human Cancer. New York: Cold Spring Harbor Laboratory, 1977; 1561-77.

5 Skog KI, Johansson MA, Jagerstad MI. Carcinogenic heterocyclic amines in model systems and cooked foods: a review on formation, occurrence and intake. Food and Chemical Toxicology 1998; 36(9-10): 879-96.

6 Reistad R, Rossland OJ, Latva-Kala KJ, Rasmussen T, Vikse R, Becher $\mathrm{G}$, et al. Heterocyclic aromatic amines in human urine following a fried meat meal. Food and Chemical Toxicology 1997; 35(10-11): 945-55.

7 Friesen MD, Rothman N, Strickland PT. Concentration of 2amino-1-methyl-6-phenylimidazo(4,5-b)pyridine (PhIP) in urine and alkali-hydrolyzed urine after consumption of charbroiled beef. Cancer Letters 2001; 173(1): 43-51.

8 Kulp KS, Knize MG, Malfatti MA, Salmon CP, Felton JS. Identification of urine metabolites of 2-amino-1-methyl-6phenylimidazo[ $[4,5-b]$ pyridine following consumption of a single cooked chicken meal in humans. Carcinogenesis 2000; 21(11): 2065-72.

9 Gorlewska-Roberts K, Green B, Fares M, Ambrosone CB, Kadlubar FF. Carcinogen-DNA adducts in human breast epithelial cells. Environmental and Molecular Mutagenesis 2002; 39(2-3): 184-92.

10 International Agency for Research on Cancer (IARC). Monographs on the Evaluation of Carcinogenic Risk to Humans, Vol. 56. Lyon: IARC, 1993; 163-242.

11 Sugimura T. Nutrition and dietary carcinogens. Carcinogenesis 2000; 21(3): 387-95.

12 Knize MG, Felton JS. Formation and human risk of carcinogenic heterocyclic amines formed from natural precursors in meat. Nutrition Reviews 2005; 63(5): 158-65.

13 Butler LM, Sinha R, Millikan RC, Martin CF, Newman B, Gammon MD, et al. Heterocyclic amines, meat intake, and association with colon cancer in a population-based study. American Journal of Epidemiology 2003; 157(5): 434-45.

14 Sinha R, Kulldorff M, Chow WH, Denobile J, Rothman N. Dietary intake of heterocyclic amines, meat-derived mutagenic activity, and risk of colorectal adenomas. Cancer Epidemiology, Biomarkers \& Prevention 2001; 10(5): 559-62.

15 Nowell S, Coles B, Sinha R, MacLeod S, Luke Ratnasinghe D, Stotts C, et al. Analysis of total meat intake and exposure to individual heterocyclic amines in a case-control study of 
colorectal cancer: contribution of metabolic variation to risk. Mutation Research 2002; 506-507: 175-85.

16 Pais P, Moyano E, Puignou L, Galceran MT. Liquid chromatography-electrospray mass spectrometry with insource fragmentation for the identification and quantification of fourteen mutagenic amines in beef extracts. Journal of Chromatography A 1997; 775(1-2): 125-36.

17 Knize MG, Dolbeare FA, Cunningham PL, Felton JS. Mutagenic activity and heterocyclic amine content of the human diet. Princess Takamatsu Symposium 1995; 23 $30-8$.

18 Kobayashi M, Hanaoka T, Nishioka S, Kataoka H, Tsugane S Estimation of dietary HCA intakes in a large-scale population-based prospective study in Japan. Mutation Research 2002; 506-507: 233-41.

19 Layton DW, Bogen KT, Knize MG, Hatch FT, Johnson VM, Felton JS. Cancer risk of heterocyclic amines in cooked foods: an analysis and implications for research. Carcinogenesis 1995; 16(1): 39-52.

20 Augustsson K, Skog K, Jagerstad M, Steineck G. Assessment of the human exposure to heterocyclic amines. Carcinogenesis 1997; 18(10): 1931-5.

21 Keating GA, Bogen KT. Estimates of heterocyclic amine intake in the US population. Journal of Chromatography, B. Analytical Technologies in the Biomedical and Life Sciences 2004; 802(1): 127-33.

22 Zimmerli B, Rhyn P, Zoller O, Schlatter J. Occurrence of heterocyclic aromatic amines in the Swiss diet: analytical method, exposure estimation and risk assessment. Food Additives and Contaminants 2001; 18(6): 533-51.

23 Byrne C, Sinha R, Platz EA, Giovannucci E, Colditz GA, Hunter DJ, et al. Predictors of dietary heterocyclic amine intake in three prospective cohorts. Cancer Epidemiology, Biomarkers \& Prevention 1998; 7(6): 523-9.

24 Wong KY, Su J, Knize MG, Koh WP, Seow A. Dietary exposure to heterocyclic amines in a Chinese population. Nutrition and Cancer 2005; 52(2): 147-55.

25 Manjer J, Carlsson S, Elmstahl S, Gullberg B, Janzon L, Lindstrom M, et al. The Malmo Diet and Cancer Study: representativity, cancer incidence and mortality in participants and non-participants. European Journal of Cancer Prevention 2001; 10(6): 489-99.

26 Manjer J, Elmstahl S, Janzon L, Berglund G. Invitation to a population-based cohort study: differences between subjects recruited using various strategies. Scandinavian Journal of Public Health 2002; 30(2): 103-12.

27 Callmer E, Riboli E, Saracci R, Akesson B, Lindgarde F. Dietary assessment methods evaluated in the Malmo food study. Journal of Internal Medicine 1993; 233(1): 53-7.

28 Riboli E, Elmstahl S, Saracci R, Gullberg B, Lindgarde F. The Malmo Food Study: validity of two dietary assessment methods for measuring nutrient intake. International Journal of Epidemiology 1997; 26(Suppl. 1): S161-73.

29 Elmstahl S, Riboli E, Lindgarde F, Gullberg B, Saracci R. The Malmo Food Study: the relative validity of a modified diet history method and an extensive food frequency questionnaire for measuring food intake. European Journal of Clinical Nutrition 1996; 50(3): 143-51.

30 Borgen E, Skog K. Heterocyclic amines in some Swedish cooked foods industrially prepared or from fast food outlets and restaurants. Molecular Nutrition \& Food Research 2004; 48(4): 292-8.

31 Persson E, Sjoholm I, Skog K. Effect of high water-holding capacity on the formation of heterocyclic amines in fried beefburgers. Journal of Agricultural and Food Chemistry 2003; 51(15): 4472-7.

32 Johansson M, Skog K, Jagerstad M. Effects of edible oils and fatty acids on the formation of mutagenic heterocyclic amines in a model system. Carcinogenesis 1993; 14(1): $89-94$.
33 Santos FJ, Barcelo-Barrachina E, Toribio F, Puignou L, Galceran MT, Persson E, et al. Analysis of heterocyclic amines in food products: interlaboratory studies. Journal of Chromatography, B. Analytical Technologies in the Biomedical and Life Sciences 2004; 802(1): 69-78.

34 National Bureau of Statistics. Occupations in Population and Housing Census 1985 (FoB 85) according to Nordic Standard Occupational Classification (Nordisk yrkesklassificering NYK) and Swedish Socio-economic Classification (Socioekonomisk indelning SEI) (in Swedish). Stockholm: Statistics Sweden, 1989; 5.

35 Taylor HL, Jacobs DR Jr, Schucker B, Knudsen J, Leon AS, Debacker G. A questionnaire for the assessment of leisure time physical activities. Journal of Chronic Diseases 1978; 31(12): 741-55.

36 Richardson MT, Leon AS, Jacobs DR Jr, Ainsworth BE, Serfass R. Comprehensive evaluation of the Minnesota Leisure Time Physical Activity Questionnaire. Journal of Clinical Epidemiology 1994; 47(3): 271-81.

37 Elmstahl S, Gullberg B, Riboli E, Saracci R, Lindgarde F. The Malmo Food Study: the reproducibility of a novel diet history method and an extensive food frequency questionnaire. European Journal of Clinical Nutrition 1996; 50(3): 134-42.

38 Cantwell M, Mittl B, Curtin J, Carroll R, Potischman N, Caporaso $\mathrm{N}$, et al. Relative validity of a food frequency questionnaire with a meat-cooking and heterocyclic amine module. Cancer Epidemiology, Biomarkers \& Prevention 2004; 13(2): 293-8.

39 Keating GA, Layton DW, Felton JS. Factors determining dietary intakes of heterocyclic amines in cooked foods. Mutation Research 1999; 443(1-2): 149-56.

40 Solyakov A, Skog K. Screening for heterocyclic amines in chicken cooked in various ways. Food and Chemical Toxicology 2002; 40(8): 1205-11.

41 Olsson V, Solyakov A, Skog K, Lundstrom K, Jagerstad M. Natural variations of precursors in pig meat affect the yield of heterocyclic amines - effects of RN genotype, feeding regime, and sex. Journal of Agricultural and Food Chemistry 2002; 50(10): 2962-9.

42 Olsson V, Skog K, Lundstrom K, Jagerstad M. Colour photographs for estimation of heterocyclic amine intake from fried pork chops of different RN genotypes indicate large variations. Food Quality and Preference 2005, 16(2): 91-101.

43 Sandhu MS, White IR, McPherson K. Systematic review of the prospective cohort studies on meat consumption and colorectal cancer risk: a meta-analytical approach. Cancer Epidemiology, Biomarkers \& Prevention 2001; 10(5): 439-46.

44 Chao A, Thun MJ, Connell CJ, McCullough ML, Jacobs EJ, Flanders WD, et al. Meat consumption and risk of colorectal cancer. Journal of the American Medical Association 2005; 293(2): $172-82$

45 Larsson SC, Rafter J, Holmberg L, Bergkvist L, Wolk A. Red meat consumption and risk of cancers of the proximal colon, distal colon and rectum: the Swedish Mammography Cohort. International Journal of Cancer 2005; 113(5): 829-34.

46 Norat T, Lukanova A, Ferrari P, Riboli E. Meat consumption and colorectal cancer risk: dose-response meta-analysis of epidemiological studies. International Journal of Cancer 2002; 98(2): 241-56.

47 Bingham SA. High-meat diets and cancer risk. Proceedings of the Nutrition Society 1999; 58(2): 243-8.

48 Felton JS, Jägerstad M, Knize MG, Skog K, Wakabayshi K. Contents in food, beverages and tobacco. In: Nagao M, Sugimura T, eds. Food Borne Carcinogens: Heterocyclic Amines. Chichester: John Wiley \& Sons Ltd, 2000; 31-72.

49 Serdula MK, Byers T, Mokdad AH, Simoes E, Mendlein JM, Coates RJ. The association between fruit and vegetable 
intake and chronic disease risk factors. Epidemiology 1996; 7(2): $161-5$.

50 Agudo A, Pera G. Vegetable and fruit consumption associated with anthropometric, dietary and lifestyle factors in Spain. EPIC Group of Spain. European Prospective Investigation into Cancer. Public Health Nutrition 1999; 2(3): 263-71.

51 Guo X, Warden BA, Paeratakul S, Bray GA. Healthy Eating Index and obesity. European Journal of Clinical Nutrition 2004; 58(12): 1580-6.

52 Becker W, Pearson M. Riksmaten 1997-98. Dietary Habits and Nutrient Intake in Sweden. Uppsala: The Swedish National Food Administration, 2002.

53 Augustsson K, Skog K, Jagerstad M, Dickman PW, Steineck G. Dietary heterocyclic amines and cancer of the colon, rectum, bladder, and kidney: a population-based study. Lancet 1999; 353(9154): 703-7.

54 Zheng W, Xie D, Cerhan JR, Sellers TA, Wen W, Folsom AR. Sulfotransferase 1A1 polymorphism, endogenous estrogen exposure, well-done meat intake, and breast cancer risk. Cancer Epidemiology, Biomarkers \& Prevention 2001; 10(2): 89-94.

55 Chen J, Stampfer MJ, Hough HL, Garcia-Closas M, Willett WC, Hennekens $\mathrm{CH}$, et al. A prospective study of $\mathrm{N}$ acetyltransferase genotype, red meat intake, and risk of colorectal cancer. Cancer Research 1998; 58(15): 3307-11.

56 Orrhage K, Sillerstrom E, Gustafsson JA, Nord CE, Rafter J. Binding of mutagenic heterocyclic amines by intestinal and lactic acid bacteria. Mutation Research 1994; 311(2): 239-48

57 Yu Z, Xu M, Santana-Rios G, Shen R, Izquierdo-Pulido M, Williams DE, et al. A comparison of whole wheat, refined wheat and wheat bran as inhibitors of heterocyclic amines in the Salmonella mutagenicity assay and in the rat colonic aberrant crypt focus assay. Food and Chemical Toxicology 2001; 39(7): 655-65.

58 Felton JS, Knize MG, Bennett LM, Malfatti MA, Colvin ME, Kulp KS. Impact of environmental exposures on the mutagenicity/carcinogenicity of heterocyclic amines. Toxicology 2004; 198(1-3): 135-45.

59 Key TJ, Schatzkin A, Willett WC, Allen NE, Spencer EA, Travis $\mathrm{RC}$, et al. Diet, nutrition and the prevention of cancer. Epidemiologic evidence of the protective effect of fruit and vegetables on cancer risk. Public Health Nutrition 2004; 7(1A): $187-200$.

60 Riboli E, Norat T. Epidemiologic evidence of the protective effect of fruit and vegetables on cancer risk. American Journal of Clinical Nutrition 2003; 78(Suppl. 3): 559S-69S.

61 Steinkellner H, Rabot S, Freywald C, Nobis E, Scharf G, Chabicovsky $\mathrm{M}$, et al. Effects of cruciferous vegetables and their constituents on drug metabolizing enzymes involved in the bioactivation of DNA-reactive dietary carcinogens. Mutation Research 2001; 480-481: 285-97.

62 Breinholt V, Lauridsen ST, Dragsted LO. Differential effects of dietary flavonoids on drug metabolizing and antioxidant enzymes in female rat. Xenobiotica 1999; 29(12): 1227-40. 